\title{
Multiple Arterial Variations in the Right Upper Limb of a Caucasian Male Cadaver
}

\author{
Múltiples Variaciones Arteriales en el Miembro Superior \\ Derecho de un Cadáver Caucásico Masculino
}

\author{
"Musaed A. Al-fayez; "Zahid Ali Kaimkhani; **Muhammad Zafar; \\ "Hasem Darwish; *Abdullah Aldahmash \& ***Abdul Aziz Al-Ahaideb
}

AL-FAYEZ, M. A.; KAIMKHANI, Z. A.; ZAFAR, M.; DARWISH, H.; ALDAHMASH, A. \& AL-AHAIDEB, A. A. Multiple arterial variations in the right upper limb of a caucasian male cadaver. Int. J. Morphol., 28(3):659-665, 2010.

SUMMARY: Anatomical variations of the arterial patterns in the upper limb have been describe in many anatomical studies, but the occurrence of four variations in a ipsilateral upper limb is rare. These arterial variations were observed in the right upper limb of a 65 -year old Caucasian male cadaver during routine dissection in the anatomy department, College of Medicine at the King Saud University, Riyadh. These arterial variations include: 1) a large common trunk of the axillary artery giving origin to subscapular artery, profunda brachii artery, common circumflex humoral artery and superior ulnar collateral artery, 2) superficial brachial artery; 3) superficial brachioulnar artery, and 4) the radialis indicis branch from superficial palmar arch. Appreciation of variations in the upper limb vessels is important due to increasing number of procedures both diagnostic and therapeutic as in breast cancer surgery, flap harvesting and arteriogaphy.

KEY WORDS: Arterial variations; Right upper limb; Caucasian; Cadaver.

\section{INTRODUCTION}

Variations of the arterial patterns in the upper limb have been the subject of many anatomical studies due to their higher incidence. These variations are common and have been reported by several investigators (Tountas \& Bergman, 1993; Rodriguez-Baeza et al., 1995; Atahan et al., 2005; Pelin et al., 2006; Claassen et al., 2006; Sieg et al., 2006; Natsis et al., 2006; Bataineh \& Moqattash, 2006; Dartnell et al., 2007; Cavolli et al., 2007; Senanayake et al., 2007; Yang et al., 2008).

Rodríguez-Niedenführ et al. (2001) conducted an extensive study on arterial variations in 384 upper limbs. They reviewed the literature on previous classifications and case reports, and devised a uniform system of nomenclature, which they revised in 2003. Variations were broadly divided into three groups based on their location in (1) the arm; (2) the arm and forearm and (3) the forearm. This led to a total of 16 variations, albeit each with their own set of minor variations. Their flexible system of terminology stands superior to other classification systems for it considers the variation as an entity along its entire extension, respects the topographical criteria and avoids use of additional terms.

The arterial variations of the upper limb have been implicated in different clinical situations. The superficial brachioulnar and superficial brachioradial arteries have been encountered during elevation of the flap (Fatah et al., 1985; Thoma \& Young, 1992; Heden \& Gylbert, 1990; Funk et al., 1995; Yuksel et al., 1999). Possible arteriographic misinterpretations have been reported when the contrast dye was injected distal to the origin of these variant arteries (Uglietta \& Kadir, 1989). Similarly, intra-arterial injection of drugs due to the proximity of normal vein puncture sites has also been reported (Thomas \& Newell, 1995). The absence of the ulnar artery resulted in hand ischemia after radial artery grafting for coronary bypass (Nunoo-Mensah, 1998). The

* Dept. of Anatomy, College of Medicine, KKUH, King Saud University, Saudi Arabia.

** Faculty of Medicine, King Fahad Medical City, Riyadh, Saudi Arabia.

**** Orthopedic Dept, College of Medicine, KKUH, King Saud University, Saudi Arabia. 
existence of a superficial radial artery implies the absence of the normal radial pulse at the wrist and has also been reported as producing problems in cannulation (Diz et al., 1998).

This report describes concomitant presence of rare arterial variations in the right upper limb: 1. A common trunk arising from second part of the axilar artery (AA); 2. Superficial brachial artery (SBA); 3. Superficial brachio-ulnar artery (SBU artery); 4) the radialis indicis branch from superficial palmar arch.

\section{CASE REPORT}

During the dissection of cadavers to prepare prosected specimens for the medical students of the Department of Anatomy, College of Medicine, King Saud University, Riyadh, an unusual branch of the axillary artery was found in one cadaver. Thereafter the arterial systems of both upper limbs were studied carefully.

A large common trunk was arising from postero-lateral surface of the second part of the AA that coursed behind between the two roots of the median nerve. It gave rise sub-scapular artery $4 \mathrm{~cm}$ from its origin, followed by another branch that divided into anterior and posterior circumflex-humeral arteries. Finally at the lower margin of the latismus dorsi muscle it ended by dividing into profunda brachii and superior ulnar collateral arteries. This profunda brachii artery accompanied radial nerve and entered into the radial groove through lower triangular space (Fig. 1 ). The largest branch was the sub-scapular artery and all these branches took the normal course.

The medial root to the median nerve passed behind the AA to join its companion to form the median nerve. The AA continued as SBA as the median nerve crossed it posteriorly to lie on the medial side in the lower half of the forearm. The SBA had a normal course and was dividing into the radial and the common interosseous arteries at the cubital fossa. It gave rise, the SBU artery, inferior ulnar collateral branch and muscular branches (Fig. 2).

The SBU artery was arising from the medial side of the middle of the SBA. It was descending deep to the deep fascia and crossed the median nerve. One inch above the elbow, piercing the deep fascia it came to lie superficial to the bicipital aponeurosis. At the cubital fossa the artery passed superficial to the muscles arising from the medial epicondyle (Fig. 2 ) (the palmaris longus muscle was absent). At the distal third of the forearm the course of the ulnar artery was normal and passed superficial to the flexor retinaculum to form the superficial palmar arch as usual. There were no branches throughout its course in the forearm and it was running superficial to the deep fascia.

The common interosseous artery passed deep to the pronator teres muscle, giving off a recurrent branch, a muscular branch to the flexor digitorum superficialis muscle (FDS), median artery, another muscular branch to flexor digitorum profundus muscle (FDP). It then, passed deep to flexor pollicis longus (FPL) to reached the interosseous membrane. It gave a posterior interosseous branch and continued as anterior interosseous artery.

The radial artery passed distally medial to the biceps tendon and the brachioradialis muscle, over the tendon of insertion of the pronator teres muscle, the FDS, the FPL. It was covered only by the skin and by superfi-

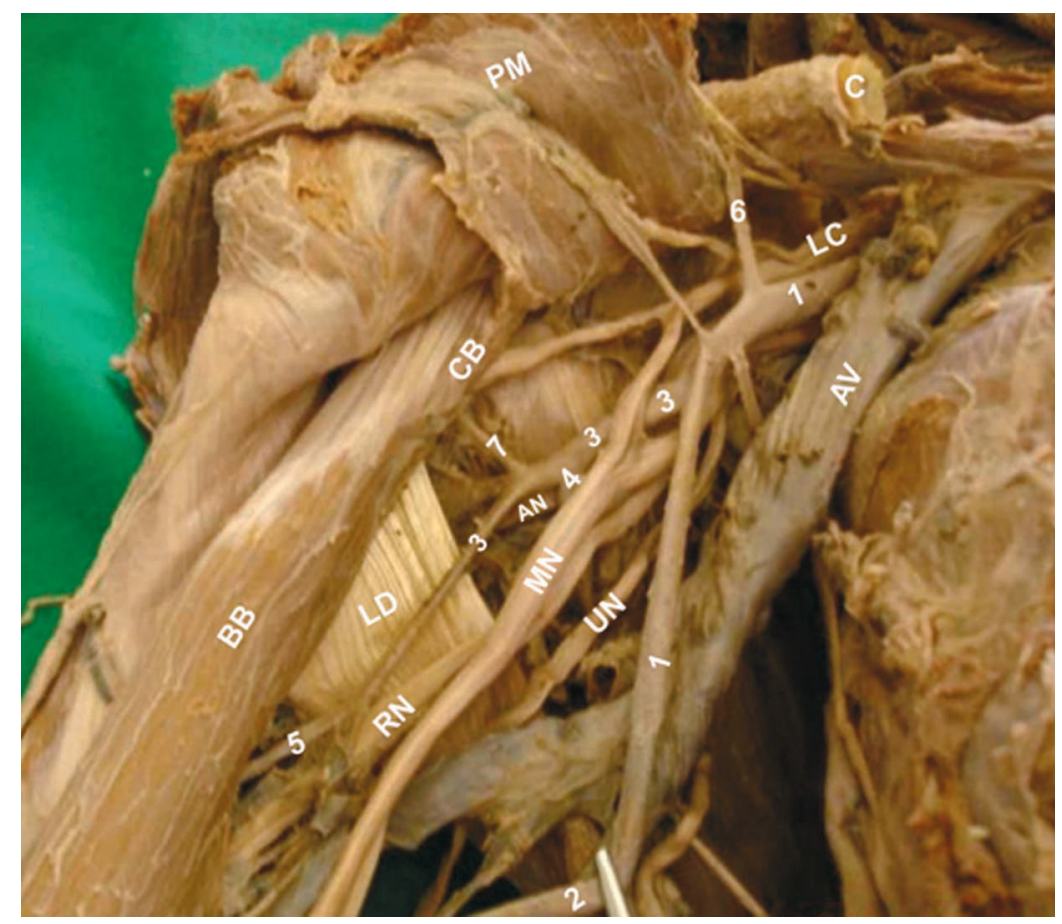

Fig. 1. Photograph of right axillary region showing the bifurcation of axillary artery and their branching pattern. Clavicle (C); Pectoralis major muscle (PM); Coracobrachialis muscle (CB); Biceps brachii muscle (BB); Latismus dorsi muscle (LD); Lateral cord (LC); median nerve (MN); ulnar nerve (UN); axillary nerve (AN); radial nerve (RN); axillary vein (AV); Axillary artery (AA); 1. Superficial axillary artery; 2. Superficial brachial artery; 3 . Deep axillary artery; 4. Subscapular artery; 5 . Profunda brachii artery; 6 . Thoraco acromial artery; 7 . Anterior circumflex humeral artery; 8. Posterior circumflex humeral artery. 


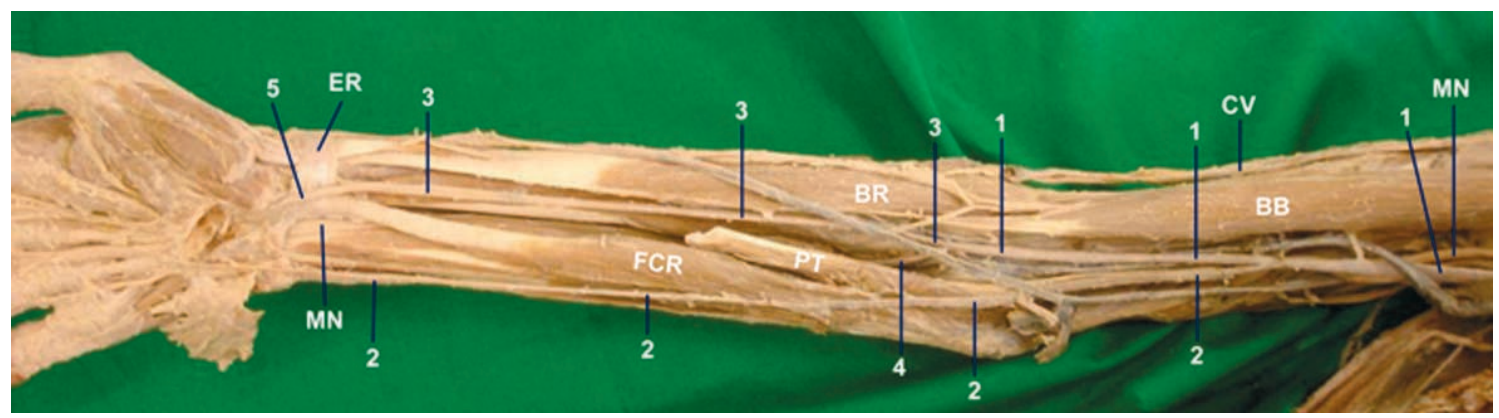

Fig. 2. Median nerve (MN); Biceps brachii muscle (BB); cephalic nerve (CV); brachioradialis muscle (BR); pronator teres muscle (PT); Flexor carpi radialis muscle (FCR); extended extensor retinaculum (ER). 1. Superficial brachial artery; 2. Superficial brachioulnar artery; 3. Radial artery; 4. Common interosseus artery; 5. Variant palmar branch of radial artery.

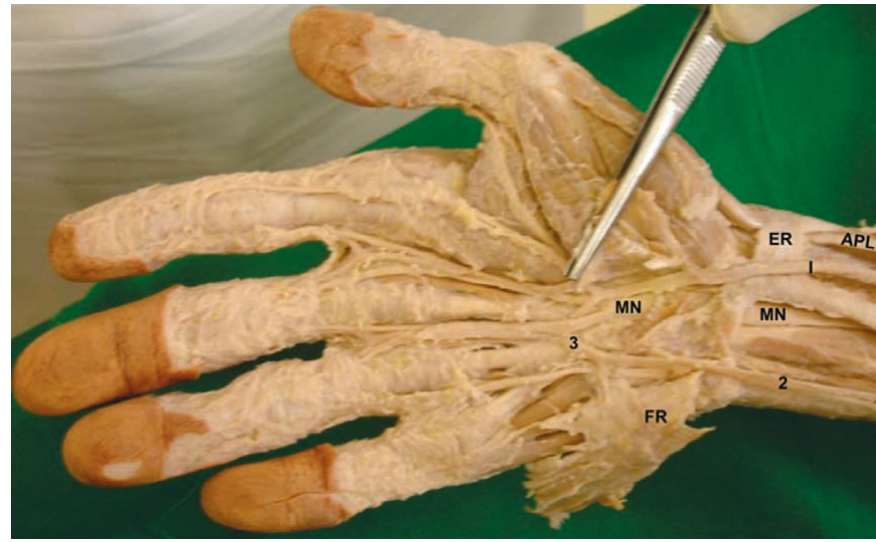

Fig. 3. Median nerve (MN); extended extensor retinaculum (ER); abductor pollicis longus (APL); flexor retinaculum. 1. variant palmar branch of radial artery ; 2. Superficial brachioulnar artery; 3. superficial palmar arch.

cial and deep fascia. The proximal attachment of the extensor retinaculum (ER) was extended to the flexor carpi radialis muscle (Fig. 3. ). The radial artery gave rise a superficial palmar branch just above this extension of ER which passed in front of ER and deep to origin of the FP brevis muscle. In the palm, it gave 2 digital branches, one for the radial side of the index finger (radialis indicis) and another for the adjacent side of index and middle finger and then, joined the SBU to complete the superficial palmar arch. The radial artery descended behind the ER, coursed deep to the tendons of the anatomical snuff box and, by passing between the 2 heads of the 1 st dorsal interosseous completed the deep palmar arch. The arterial pattern of the left upper limb was normal (Fig. 4).

\section{DISCUSSION}

Normally variations in anatomy consists of a range of morphologies that are most typical and others less frequent, which are called variations and not considered abnormal (Willan



Fig. 4. Sketch of right upper limb arterial variations. Median nerve (MN); lateral root to median nerve (LR); medial root to median nerve (MR). Axillary artery; 2. Superficial brachial artery; 3.deep axillary artery; 4 . subscapular artery; 5.profunda brachii artery; 6.superior ulnar collateral artery; 7. anterior circumflex humoral artery; 8. posterior circumflex humoral artery; 9. Superficial brachioulnar artery; 10. common interosseus artery; 11 . radial artery $; 12$. variant palmar branch of radial artery ;13. inferior ulnar collateral artery ;14. ulnar recurrent artery. 
\& Humpherson, 1999). Variations, no matter how considerable they are, affect every part of the human body. These variations provide a framework for reviewing common morphology and embrogenesis of the structures (Zucconi et al., 2002).

Variations of the normal arterial pattern in the upper limb occur frequently (Tountas \& Bergman; RodriguezBaeza et al.; Atahan et al.; Pelin et al.; Claassen et al.; Sieg et al.; Natsis et al.; Bataineh \& Moqattash; Ysuruo et al. 2006; Dartnell et al.; Cavolli et al.; Senanayake et al.; Yang et al.). Rodriguez-Niedenführ et al. presented a detail study and a meta analysis of arterial variations in the upper limb . They unified variable terminology used previously into a homogenous and complete classification, with 12 categories covering all the previously reported variant patterns of the arm and forearm.

Anomalies in the axillary artery with regard to origin, course and branching are infrequent (Tan \& Tan, 1994). This large branch from the second part of the AA was not described in the available data and not mentioned in the compendium of human anatomic variations (Bergman et al., 1988). Some authors (Jurjus et al., 1999; Yotova \& Novakov, 2004) reported similar cases but they named this branch as the variant AA with some changed pattern of branches.

The profunda brachii, largest branch of the brachial, shows considerable variations in its origin. In 55\% of cases, it arises as a single trunk at the level of the tendon of teres major muscle. It may arise from the axillary artery $(22 \%)$, as common trunk with the superior ulnar collateral artery in $22 \%$, or as a branch of the posterior circumflex humeral artery (7\%) (Tountas \& Bergman). In this study, the profunda brachii and superior ulnar collateral arteries were the terminal branches of a common trunk from the A A.

Using the terminology of Rodriguez-Niedenfuhr et $a l$. our case most closely resembles a SBA and SBU artery in the arm and fore arm.

The SBA is defined as the artery coursing in front of, rather than behind the median nerve. After adopting its superficial course, the SBA does not show relevant morphological details and at the level of the elbow it branches into the forearm arteries (Rodriguez-Niedenführ et al.). The incidence of SBA varies from $3.6 \%$ to $9.6 \%$. This arterial pattern was more frequent in male and on the right side (Rodriguez-Niedenführ et al.). The SBA sends a branch posteriorly, providing the normal branches of the brachial artery i.e. the profunda brachii, anterior and posterior circumflex humeral arteries, superior ulnar collateral. We also reported the SBA in the right UL of male cadaver.
However, in this cadaver, rather all these arteries were arising from a common trunk arising from AA and a SBU artery was given off from the middle of SBA.

The SBA does not present any further deviation from the norm and at the elbow it branches into all the forearm arteries (Rodriguez-Niedenführ et al.). Whereas, in our case the SBA gave off the SBU artery in the middle $3^{\text {rd }}$ of the arm and at elbow and divided into the radial and common interosseous trunk.

The SBU is defined as an ulnar artery with a high origin, and which courses over the superficial forearm muscles (Rodriguez-Niedenführ et al.). The presence of SBU artery seems to be a rare variation with an incidence of $0.7 \%$ -7\% (Rodriguez-Niedenführ et al.; D'costa et al., 2004; Chin \& Sing, 2005; Senanayake et al.). It has been reported with different terminologies (Lippert \& Pabst, 1985; Nakatani et al., 1996, 1997; 1998). The SBU most frequently arise from the SBA (Rodriguez-Baeza et al.) or from the axillary artery (Nakatani et al., 1996). In case originating from the brachial artery, it crosses the median nerve to run superficial to it along the nerve. Rodriguez-Niedenführ et al. reported sex and laterality about the SBU artery. It was unilateral in male cadavers but bilateral in females.

In the forearm, the SBU artery adopts a course between the deep fascia and superficial flexor muscles and eventually takes its usual position on the lateral aspect of the ulnar nerve in the middle third of the forearm. In this case, the brachial artery then divides at its normal level into the radial and the interosseous trunk, then later sending off the recurrent ulnar artery (Rodriguez-Baeza et al.; Rodriguez-Niedenführ et al.). The SBU artery has been observed together with other arterial variations (RodriguezBaeza et al.; Rodriguez-Niedenführ et al.).

In this repot the SBU artery was also found in the right UL of a male cadaver with other arterial variations. It was also arising from the SBA, adopted a course between the deep fascia and superficial flexor muscles. The SBA also divided at its normal level into the radial and the interosseous trunk.

The superficial palmar branch of the radial artery communicated with the SBU artery and completed the arch in $60 \%$.The radialis indicis branch arises from the superficial arch in $13 \%$ of individual and supplies solely the radial side of the index finger (Tountas \& bergman) and we observed this too.

Clinical implications. Vascular anomalies present in common surgical sites tend to increase the likelihood of damage during surgery. The clinical importance of the 
described arterial variations is beyond doubt. Failure to recognize these vascular anomalies may results in compromised surgical outcome. During breast cancer surgery surgeons have to protect the axillary vessels during removal of lymph nodes (Jurjus et al.). Appreciation of the vascular supply of the forearm and hand allows the surgeon to repair the injured hand or finger, correct vascular formations, and use many skin, muscle, and fascial flaps for reconstruction (Brown et al., 1999).

The clinical importance of SBU artery should not be underestimated as several cases of intra-arterial injection of drugs and subsequent amputations have been reported (Ohana et al., 1999; Goldberg et al., 1984). Superficial position of the ulnar artery makes it more vulnerable to trauma and thus hemorrhages. In our described case the ulnar artery was superficial to the bicipital aponeurosis and in a clinical setting such a variant could easily be mistaken for a vein. Such misinterpretation could lead to intra-arterial injection and difficulties in angiographic procedures (Chin $\&$ Sing). It also has would have a higher risk of getting damaged during forearm surgery. Demonstration of patency of the ulnar artery is very important before raising a free radial forearm flap, and can be established by Doppler flow meter. After such a flap forearm blood supply would depend entirely on the patent ulnar artery. Hence any abnormal positions or divisions of the ulnar artery are important to identify before such surgery (Latika \& Rima, 2005). The importance of this variant is growing with the increasing use of radial arteries as conduits in coronary bypass (Joseph et al., 2005).

Embryological basis. Variations of the arterial pattern of the UL can be explained on the basis of the embryological development. Developmentally, the UL bud is initially supplied by a vascular plexus derived from 4 or 5 consecutive intersegmental branches of the dorsal aortae. Very early in the development, the $7^{\text {th }}$ intersegmental artery forms the main artery (axis artery) of the developing $\mathrm{U} L$ bud. The axis artery gives rise to the subclavian, axillary, brachial and interosseous arteries. Other branches are added subsequently to the axis artery. First is the median artery. The ulnar and the radial arteries arise from the axis artery later. Because of this temporal succession of emergence of principle arteries, anomalies of forearm vasculature occur (Williams, 1995). Rodríguez-Niedenführ et al. studied 112 human embryos and reported that the arterial pattern of the upper limb develops from an initial capillary plexus by a proximal and distal differentiation, due to maintenance, enlargement and differentiation of certain capillary vessels, and the regression of others. They found a number of UL arterial variations and suggested that the variations arise through the persistence, enlargement and differentiation of parts of the initial network which would normally remain as capillaries or even regress.

In conclusion, the occurrence of the these variations in one UL is rare and very important clinically. The knowledge of such variations is important; not only for surgeons but also for other medical and nursing staff because intravascular canulations are commonly performed by them. Palpating for a superficial pulse over the canulation site before such a procedure will probably minimize the risk of damaging an artery and subsequent bleeding.

This also emphasizes the importance of preoperative arterial Doppler or angiography to correctly identify the regional anatomy of the vessels in certain procedures. Otherwise, the presence of the variations may be unexpectedly encountered during cases of vascularized forearm flap transfer or elective vascular surgery especially in the hand.

AL-FAYEZ, M. A.; KAIMKHANI, Z. A.; ZAFAR, M.; DARWISH, H.; ALDAHMASH, A. \& AL-AHAIDEB, A. A. Múltiples variaciones arteriales en el miembro superior derecho de un cadáver caucásico masculino. Int. J. Morphol., 28(3):659-665, 2010 .

RESUMEN: En numerosos estudios se han descrito las variaciones anatómicas de los patrones arteriales en el miembro superior, sin embargo, la aparición de cuatro variantes ipsilaterales en un miembro superior es poco frecuente. Estas variaciones arteriales fueron observadas en el miembro superior derecho de un cadáver caucásico masculino de 65 años de edad, durante la disección de rutina en el Departamento de Anatomía de la Facultad de Medicina de la Universidad de King Saud, en Riad. Estas variaciones arteriales incluyen: 1) un gran tronco común de la arteria axilar dando origen a las arterias subescapular, braquial profunda, braquial común y colateral ulnar superior; 2) la arteria braquial superficial; 3) la arteria braquioulnar superficial y 4) la rama radial del índice desde el arco palmar superficial. La observación de variaciones en los vasos del miembro superior es importante debido al número cada vez mayor de procedimientos diagnósticos y terapéuticos, como en la cirugía del cáncer de mama, la recolección de colgajos y arteriografías.

PALABRAS CLAVE: Variaciones arteriales; Miembro superior derecho; Caucásico; Cadáver. 


\section{REFERENCES}

Atahan, E.; Cetinus, E. \& Yasim, A. Superficial brachial artery. Vasa, 34(3):195-7, 2005.

Bataineh, Z. M. \& Moqattash, S. T. A complex variation in the superficial palmar arch. Folia Morphol. (Warsz), 65(4):406-9, 2006.

Bergman, R. A.; Thompson, S. A.; Afifi, A. K. \& Saadeh, F. A. Compendium of human anatomic variation. Munich, Urban and Schwarzenberg, 1988. pp.72-4.

Brown, M. J.; Edstorm, L. E. \& Zienowicz, R. J. A symptomatic radial artery anomaly and its surgical treatment. J. Hand Surg. Am., 24(1):178-81, 1999.

Cavolli, R.; Eryilmaz, S.; Kaya, B. \& Ozyurda, U. Report of the anatomic variation of the brachial artery in a patient undergoing transradial cardiac catheterization. J. Vasc. Nurs., 25(1):19-20, 2007.

Chin, K. J. \& Sing, K. The superficial ulnar artery--a potential hazard in patients with difficult venous access. $\mathrm{Br} . \mathrm{J}$. Anaesth., 94(5):692-3, 2005.

Claassen, H.; Schmitt, O. \& Wree, A. Variations of the A. axillaris and the crural arteries in the same human individual--multiple repetitions of the mammalian plesiomorphic constellation of the arteries. Ann. Anat., 188(1):39-48, 2006.

Dartnell, J.; Sekaran, P. \& Ellis, H. The superficial ulnar artery: incidence and calibre in 95 cadaveric specimens. Clin. Anat., 20(8):929-32, 2007.

D'costa, S.; Shenoy, B. M. \& Narayana, K. The incidence of superficial arterial pattern in the human upper limb extremities. Folia Morphol. (Warsz), 63(4):459-63, 2004.

Diz, J. C.; Ares, X.; Tarrazo, A. M.; Alvarez, J. \& Meaños, E. R. Bilateral superficial radial artery at the wrist. Acta Anaesthesiol. Scand., 42(8):1020, 1998.

Fatah, M. F.; Nancarrow, J. D. \& Murray, D. S. Raising the radial artery forearm flap: the superficial ulnar artery 'trap'. Br. J. Plast. Surg., 38(3):394-5, 1985.

Funk, G. F.; Valentino, J.; Mcculloch, T. M.; Graham, S. M. \& Hoffman, H. T. Anomalies of forearm vascular anatomy encountered during elevation of the radial forearm flap. Head Neck, 17(4):284-92, 1995.
Goldberg, I.; Bahar, A. \& Yosipovitch, Z. Gangrene of upper extremity following intra-arterial injection of drugs. A case report and review of the literature. Clin. Orthop. Relat. Res., 188:223-9, 1984.

Heden, P. \& Gylbert, L. Anomaly of the radial artery encountered during elevation of the radial forearm flap. J. Reconstr. Microsurg., 6(2):139-41, 1990.

Jurjus, A. R.; Correa-De-Aruaujo, R. \& Bohn, R. C. Bilateral double axillary artery: embryological basis and clinical implication. Clin. Anat., 12(2):135-40, 1999.

Lippert, H. \& Pabst, R. Arterial Variations in Man. München, J. F. Bergmann, 1985. pp.71-3.

Latika, A. \& Rima, D. R. Superficial ulnar artery. A case report. Indian J. for the Practising Doctor, 2(3), 2005.

Joseph, J.; Ranjit, D. \& Jatin, D. Superficial ulnar artery. Eur. J. Cardiothorac. Surg., 28:495-6, 2005.

Natsis, K.; Papadopoulou, A. L.; Paraskevas, G.; Totlis, T. \& Tsikaras, P. High origin of a superficial ulnar artery arising from axillary artery: anatomy, embryology, clinical significance and a review of the literature. Folia Morphol. (Warsz), 65(4):400-5, 2006.

Nakatani, T.; Tanaka, S.; Mizukami, S.; Shiraishi, Y. \& Nakamura, T. The superficial ulnar artery originating from the axillary artery. Ann. Anat., 178(3):277-9, 1996.

Nakatani, T.; Tanaka, S. \& Mizukami, S. Superficial brachial artery continuing as the common interosseous artery. $J$. Anat., 191(1):155-7, 1997.

Nakatani, T.; Tanaka, S. \& Mizukami, S. Superficial ulnar artery originating from the brachial artery and its clinical importance. Surg. Radiol. Anat., 20(5):383-5, 1998.

Nunoo-Mensah, J. An unexpected complication after harvesting of the radial artery for coronary artery bypass grafting. Ann. Thorac. Surg., 66(3):929-31, 1998.

Ohana, E.; Sheiner, E. \& Gurman, G. M. Accidental intraarterial injection of propofol. Eur. J. Anaesthesiol., 16(8):569-70, 1999.

Pelin, C.; Zagyapan, R.; Mas, N. \& Karabay, G. An unusual course of the radial artery. Folia Morphol. 65(4):410-3, 2006. 
Rodríguez-Baeza, A.; Nebot, J.; Ferreira, B.; Reina, F.; Pérez, J.; Sañudo, J. R. \& Roig, M. An anatomical study and ontogenetic explanation of 23 cases with variations in the main pattern of the human brachio-antebrachial arteries. J. Anat., 187(2):473-9, 1995.

Rodríguez-Niedenführ, M.; Vázquez, T.; Nearn, L.; Ferreira, B.; Parkin, I. \& Sañudo, J. R. Variations of the arterial pattern in the upper limb revisited: a morphological and statistical study, with a review of the literature. J. Anat., 199(5):547-66, 2001.

Sieg, P.; Jacobsen, H. C.; Hakim, S. G. \& Hermes, D. Superficial ulnar artery: curse or blessing in harvesting fasciocutaneous forearm flaps. Head Neck, 28(5):447$52,2006$.

Senanayake, K. J.; Salgado, S.; Rathnayake, M. J.; Fernando, R. \& Somarathne, K. A rare variant of the superficial ulnar artery, and its clinical implications: a case report. J. Med. Case Reports, 1:128, 2007.

Tan, C. B. \& Tan, C. K. An unusual course and relations of the human axillary artery. Singapore Med. J., 35(3):2634,1994 .

Thoma, A. \& Young, J. E. The superficial ulnar artery "trap" and the free forearm flap. Ann. Plast. Surg., 28(4):370$2,1992$.

Thomas, R. \& Newell, R. Anomalous arteries in the upper limb. Clin. Anat., 7:57, 1995.

Tountas, C. P. \& Bergman, R. A. Anatomic variations of the upper exterimities. New York, Churchill Livingstone, 1993. pp.197-210.

Uglietta, J. P. \& Kadir, S. Arteriographic study of variant arterial anatomy of the upper extremities. Cardiovasc. Intervent. Radiol., 12(3):145-8, 1989.

Willan, P. L. \& Humpherson, J. R. Concepts of variation and normality in morphology: important issues at risk of neglect in modern undergraduate medical courses. Clin. Anat., 12(3):186-90, 1999.

Williams, P. L. Arteries of the upper limb. Grays anatomy. Great Britain, Churchill Livingstone, 1995. pp.318-20.

Yang, H. J.; Gil, Y. C.; Jung, W. S. \& Lee, H. Y. Variations of the Superficial Brachial Artery in Korean Cadavers. J. Korean Med. Sci., 23(5):884-7, 2008.
Yotova, N. \& Novakov, S. Unilateral double axillary artery. Clin. Anat., 17(2):149-51, 2004.

Yuksel, M.; Yuksel, E.; Weinfeld, A. B. \& Shenaq, S. M. Superficial ulnar artery: embryology, case report and clinical significance in reconstructive microsurgery. $J$. Reconstr. Microsurg., 15(6):415-20, 1999.

Ysuruo, Y.; Ueyama, T.; Ito, T.; Nanjo, S.; Gyoubu, N.; Satch, K.; Iida, Y. \& Nakai, S. Persistent median artery in the hand: a report with a review of the literature. Anat. Sci. Int., 81(4):242-52, 2006.

Zucconi, W. B.: Guelfguat, M. \& Solounias, N. Approach to the educational opportunities provided by variant anatomy illustrated by discussion of a duplicated inferior vena cava. Clin. Anat., 15(2):165-8, 2002.

Correspondence to:

Prof. Dr. Muhammad Zafar

Department of Anatomy, Faculty of Medicine

King Fahad Medical City, King Saud University

Riyadh, PO Box 50946, 11525

Saudi Arabia

Tel.:00966-1-2935238, 00966-1-2889999

Tel. Pakistan: 0092-334-3311328

Email:zafardoctor@hotmail.com mzafer@kfmc.med.sa

Received: 20-03-2010

Accepted: 02-06-2010 
